\title{
A Conceptual Approach to Student Study Printing: The Role and Place of Creative Composition
}

\author{
Oros Ivan Vasilyevich \\ Senior Lecturer of the Department of Theory and Methodology of Decorative \\ Arts, graphic arts and graphic faculty of the State institution "South Ukrainian \\ National Pedagogical University named after K. D. Ushinsky"
}

\begin{abstract}
The article reveals that in the formation of creative thinking, printed graphics - prints occupy a special place. It turns out that the issues of teaching creative composition in printed graphics - printmaking under the conditions of the art and graphic faculties of pedagogical universities are not sufficiently disclosed. The conceptual approach to teaching students of the art-graphic faculty of creative composition is shown. Of all the variety of methodological means of activating the process of teaching creative prints, special attention is paid to the following: highlighting in the program basic, leading theoretical knowledge and artistic and practical skills that reflect both the foundations of the traditional course of academic drawing and the specifics of the specialty; the use of special educational tasks (both in the image from nature and from memory) for creative associations with decorative images; the use of special educational tasks for the development of creative imagination in the process of drawing from life and performing artistic compositions. It is emphasized that in the conceptual approach to the creative composition was attached to the concept of the artistic image and the principles of image formation, and an important stage of the work was to create a sketch of the creative composition, which is based on the artistic image. Based on the conceptual approach to teaching students of the art-graphic faculty of creative composition, the established fundamental conditions for its use are indicated. The conclusions prove that the conceptual approach to teaching students of the art-graphic faculty of creative composition is based on certain provisions. It is argued that the role and place of the creative composition is manifested in the creation of conditions for understanding that the basics of the synthesis of such important components as the theme, idea and emotional evaluation of the depicted phenomena are the content of the work of art. The creative composition provides students with an understanding that works of art are contingent, and their conventions are permissible to a certain face, and artistic images in them are conditional with admission to a certain face.
\end{abstract}

Keywords: printed graphics, printmaking, creative thinking, artistic image, composition, creative composition.

Introduction. Relevance of research. In the complex of tasks related to the training of artists - educators, those installations that lay the foundations of special art and graphic skill are always relevant. Systematic studies of various types and subspecies of printed graphics, studying the technique and technology of print art actively influence the process of formation of students' compositional vision. In the process of educational and creative activities in the workshop of graphics, students of art and graphic faculties of pedagogical universities receive theoretical knowledge and practical skills in creating graphic compositions, get acquainted with 
the traditions and techniques of art and print graphics. The practical activities of students in the workshop of graphics in the study of printmaking are fundamental, as they actively promote art education, develop creative abilities in the field of graphic composition, and activate creative thinking.

In the formation of creative thinking, printed graphics - prints occupy a special place. In theory, this is knowledge; in practice, it is the ability to freely operate this knowledge, the ability to create a creative atmosphere, and to observe consistency in the implementation of tasks. Compositional and creative activities and the educational process in the workshops of graphic workshops at the graphic arts faculties of pedagogical universities require a comprehensive study and in-depth study of all their aspects, conceptual approaches to the process itself. In this regard, every research that reveals the theory and practice of teaching and educating students in print classes is important.

The degree of development of the problem. An analysis of the psychological and pedagogical literature and the practical experience of artists and educators shows that many researchers have addressed the problem of using art and printed graphics in pedagogical practice. Such creative scientists, psychologists as B. G. Ananyev, D. B. have devoted their works to the problem of creative, productive thinking and creativity. Epiphany A.V. Brushlinsky, L.C. Vygotsky, V.V. Davydov, S.V. Konovets, A.M. Matyushkin, S.L. Rubinstein, B.M. Teplov, Ya.V. Ponomarev, O.K. Tikhomirov, P.M. Jacobson and others. Certain aspects of creative thinking, as a kind of specific generalization in art, in the fine arts of students of art schools, schoolchildren are considered in studies, publications by N.N. Volkova, E.I. Ignatiev, B.C. Cousin, B.G. Lukyanova, V.K. Lebedko, S.P. Lomova, L. G. Medvedev, I.M. Ryazantseva, N.N. Rostovtseva, N.I. Reznichenko and others.

The determination of the state-of-the-art education of students and youth by means of art and printed graphics, as well as the process of educational and creative activity during practical classes in the graphic workshop, is paid attention to the works of N.N. Anisimov, A.D. Alekhina, G.G. Vinogradova, V.K. Lebedko, V.V. Koreshkova, V.S. Kuzin, B.T. Likhachev, N.S. Bogolyubov, N.N. Rostovtsev, N.I. Tkachenko, A.S. others. The role of art and printed graphics in the classes of students of graphic arts faculties is reflected in the writings of B. 
Klabunovsky, V. A. Eremina, M.I. Sukharev, A. Mazhug, V. Yesipov, N. Alimasova and others.

Insufficiently highlighted aspects of the problem. Current practice demonstrates the lack of a comprehensive study of the conceptual possibilities of printmaking. The issues of teaching creative composition in printed graphics - printmaking under the conditions of the art and graphic faculties of pedagogical universities are not sufficiently disclosed.

The purpose of the study is to reveal the theoretical foundations of a conceptual approach to teaching students printmaking and identify the stages of the formation of creative thinking when performing a composition of graphic works. To substantiate the role and place of creative composition in the process of practical engraving.

The main content (research methodology). In the modern art - pedagogical methodology of teaching, a great deal of attention is paid to creative educational projects, which in fact can be a characteristic of every composite decision - creative in its essence. In this connection, IV Pastir points out, "the most effective component of teaching methods for future teachers artists, is an important factor in the development of their creative abilities, imaginative thinking, aesthetic taste, and so on. we consider the method of creative educational projects based on the research and search activities of students in the process of solving problems of a problematic nature "[1, p. 224].

The general methodological base and theoretical research is the work on the problems of art education, where the following methods and approaches are fundamental: the study, analysis and generalization of scientific methodological work on the issue; study and analysis of curricula of higher educational institutions; the study of dissertation research, periodicals; pedagogical observations, conversations, questionnaires during the period of experimental studies; analysis of the educational and creative activities of students in the graphic workshop, as well as analysis of the creative work of professional graphic artists, famous masters of printed graphics; experimental work in the workshop of graphic arts of the graphic arts faculty; analysis of the composition of modern creative works in print technique $[1,2,3,4,5]$.

Of all the variety of methodological means of activating the process of teaching creative prints, special attention is paid to the following: highlighting in the program basic, leading 
theoretical knowledge and artistic and practical skills that reflect both the foundations of the traditional course of academic drawing and the specifics of the specialty; the use of special educational tasks (both in the image from nature and from memory) for creative associations with decorative images; the use of special educational tasks for the development of creative imagination in the process of drawing from life and performing artistic compositions.

The main content (Discussion). The study of dissertation research, work experience at the Faculty of Graphic Arts in the graphic print workshop allowed us to conclude the relevance of the formation of creative thinking among students. According to D.K. Gagishvili, the tasks of effectively forming creative thinking among students of art majors and making significant adjustments require the development of new methods for teaching a course in graphics, and this, in turn, determines the need for a number of experimental studies [2]. In agreement with R. Ch. Barshits, we highlight the position that classes with a "creative graphic composition" can be an effective means of aesthetic education and art education of students, provided that printmaking will be presented as a special form of artistic (graphic) comprehension of the world and the reality surrounding us ; studying the history of prints will address the most important tasks of creative education; the theory and practice of teaching print-making to students of artgraphic departments should be based on advanced technologies of the psychological, pedagogical, aesthetic and philosophical sciences of the past and present; The methodological model of teaching and educating students of graphic arts faculties in printmaking classes will be substantiated and confirmed both theoretically and practically - by the results of many experimental studies conducted at different times and in different universities [3].

The conceptual approach to teaching students of the art-graphic faculty of creative composition consisted of the following: the initial level of development of art and graphic preparation for a compositional solution was determined; studied the level of compositional vision in practical exercises on the printmaking technique; training was monitored; analyzed the level of development of aesthetic taste. The additions were: the study and development of some hidden aspects of the manifestation of students' creative activity during classes in a graphic composition in a print workshop; determination of the level of development of students' creative abilities (the embodiment of the idea of ??graphic composition in a particular printed material) by the method of psychological attitudes; study and analysis of the results of 
educational and creative activities of students in the workshop of graphics in order to determine their compositional and creative activity in the field of prints.

Step by step, the conceptual approach was as follows. There was a general idea that printmaking is one of the branches of graphics, and printmaking means a graphic work, printed from any printing form, processed in one way or another, printing: in a machine or by hand, and an independent value, with that. The circulation of received prints can range from several pieces to several thousand copies, with all prints being considered as originals.

Subsequently, attention was paid to a general understanding of the composition and its basic capabilities. Students were advised that composition is the arrangement of all parts of the work in space, that there is no uniquely theory of composition, there are only general principles, rules and techniques. From the outset it was stated: formats of a plane composition. Of great importance for flat (standard printing) compositions is the boundary of the image field. The elements of the composition, located near the center, are perceived to lie deep, and the flat field becomes spacious. Elements located on a homogeneous field close to the edge, except lying on the surface, in the plane of the frame; The most common image formats are rectangular, round, oval. The rectangular, elongated vertical format gives the feeling of height, aspiration up. The most commonly used is the rectangular gold section format. It is the most balanced and closed.

In our conceptual approach to creative composition, the concept of artistic image and the principles of image formation were of great importance. So it was stated that works of art are conditional, their conventions are admissible to a certain face, and artistic images in them are conditional with admission to a certain face. Artistic convention loses itself as soon as it becomes reality, and the distance between real emotions in relation to artistic convention may increase or decrease depending on the specificity of the image, as well as on the historical tradition of the cultures. It was reported that the peculiarity of the artistic image lies in the fact that it is an ideal system (closed, integral) - a kind of micro-world, and also that it belongs to the macrosystem of culture. The capacity for a certain imagination is an integral part of the perception of the image, it is the interdependent facets of a single process, since the process of creating an image with the help of imagination prompts and activates the author to add something invisible, or to say something incomplete - a hint. 
In the course of training it is emphasized that an important stage of work is the creation of a sketch of a creative composition, which is based on an artistic image. The sketch should be well thought out and worked, it is necessary to find out where there will be light, and where dark places. From the conceptual approach to teaching students of the art-graphic faculty of creative composition, it is possible to distinguish the established fundamental principles of graphic education and their application: special graphic development of objects, their parts, which have a special purpose for creating an artistic image in a creative composition; getting skills in imagination; development of skills of abstraction of specific subject visual forms, fluency in th e abstracted image method according to the representation and translation of a specific objective image into abstract; development of skills for generalizing tonal gradations, translating a tonal-volumetric image into a silhouette or linear-planar; mastery of special compositional techniques of a decorative nature using color, ornament; mastering the widest possible range of technical means, materials and methods of work in terms of creative search for their special and decorative capabilities.

Based on the conceptual approach to teaching students of the art-graphic faculty of creative composition, it is possible to distinguish the established fundamental conditions for its use: disclosing the scientific and theoretical foundations for the formation of students' creative thinking and psychological patterns of performing graphic works as a creative expression of a student's personality; understanding of each student's creative thinking as the most important factor in the development of his personality, artistic abilities and the conditions for successful work in creating a creative composition; development and pedagogical experimental model for the development of creative thinking of students by means of graphics; identify individual psychological characteristics in the professional and artistic development of students in the classroom graphics; development and experimental testing of methodological ways and means of enhancing the learning process of graphic means of image based on developed creative thinking.

Conclusions. On the basis of the conducted research it is possible to make certain generalizations:

- The conceptual approach to teaching students of the art-graphic faculty of creative composition is based on the following principles: success in teaching creative composition in 
art and print graphic prints is due to the creative use of the relationships between different types of fine art, the optimal ratio of theoretical and practical studies, degree in comprehension and mastering the language of graphic art, the ability to apply acquired knowledge and technical skills in creative works; Art and print graphics in combination with classes in other special types of visual arts (painting, graphics, sculpture, arts and crafts, literature, music) have great potential creative opportunities in the systematic development of creative abilities. The purposeful substantiated realization of these opportunities in practical exercises in the workshop of printed graphics acts as a pedagogical necessity; The developed and tested method of pedagogical installation activates the development of students' creative abilities in the classroom.

- From our conceptual approach to the beginning of creative composition of students, the important goal was to create an artistic image. The role of this small number of creative compositions is manifested in the fact that you can learn more about thinking about the basics of synthesizing such important components, such as the theme, the idea and the idea of evaluating the images of the creatures, as well as the artistic creation. Creative work is needed for students who want to create music, and music is permissible to the extent of singing, and artistically represent them in admission to the limit of singing.

Prospects for further research. In our opinion necessary new approach to printed graphics in the educational process as a type of artistic art is important, which has a significant influence on the education of a creative personality - students of pedagogical universities.

\section{References}

1. Pastor, I. V. (2018) Fundamentals of pedagogy of artistic creativity: a monograph. Ishmael: Irbis. - 444 p.

2. Gagishvili, D. K. (2004) Development of creative thinking at students of art specialties of high schools by means of graphics: Dissertation..candidate .. teacher .. of sciences. - special ... VAK 13.00.02 - Theory and methodology of training and education (by fields and levels of education). Moscow. - $156 \mathrm{p}$.

3. Barzits, R. Ch. (2001) Theory and practice of teaching the printmaking students of the artgraphic faculties of pedagogical universities: Dis...Dr. Ped. Sciences: 13.00.00. Moscow. $543 \mathrm{p}$.

4. Verba, I. (1968) The art of graphics. K.: Soviet School. - 100 p.

5. Goncharov, A. (1960) On the art of graphics. M.: Young Guard. - 344 p. 
6. Kolicheva, T. V. (2004) Scientific and artistic knowledge: their specificity and interaction: Author's abstract. dissertation ... Cand. philosopher. Sciences: 09.00.01. - Hark. nat. them. V. N. Karazin. H. - 17 p.

7. A New Look at the Art of Ukrainian Graphics of the XX Century // Art Horizons (2002). Issue 3. K.: AMU. - P. 40-45.

8. Timoshevsky, V. (1995) Print. Kharkiv. - 93 p.

9. Khristenko, V. (2007) Copyright printing techniques. Kharkiv: Color. - 721 p. 